\title{
Goronary Steal due to Great Saphenous Vein Graft and Pulmonary Vasenlature Fistula Managed by Goronary Angioplasty
}

Christian GERGES', Michel FEGHALI', Moussa ABI GHANEM², Fadi ABOU JAOUDEH ${ }^{3}$

Departments of 'Vascular Surgery, ${ }^{2}$ Cardio-thoracic Surgery, ${ }^{3}$ Medicine Cardiology

Division; St Georges Hospital University Medical Center, Beirut, Lebanon.

\section{Abstract:}

Formation of fistulous connection between great saphenous vein graft and pulmonary vasculature after coronary artery bypass graft (CABG) is a rare event, which can result in recurrence of symptoms ranging from stable angina to myocardial infarction related to coronary steal phenomenon. We hereby report a case of a 63 years old man who was detected to have such a fistulous communication leading to coronary steal syndrome as the cause of effort angina 12 years after CABG. Coronary angioplasty and stenting of left anterior descending artery resulted in resolution of symptoms.

Key words: Angina, Angioplasty, Coronary Artery Bypass, Myocardial Infarction, Saphenous Vein.

\section{Introduction}

Formation of fistulous connection between saphenous vein grafts and pulmonary vasculature after coronary artery bypass graft (CABG) is a rare event, which can be asymptomatic or result in recurrence of symptoms ranging from stable angina to myocardial infarction related to coronary steal phenomenon $[1,2]$.

\section{Case Report}

A 63 years old man underwent $C A B G 12$ years ago for multiple lesions involving proximal and distal left anterior descending artery (LAD), common right coronary artery ( $R C A$ ) and marginal coronary artery. Bypass consisted of reversed saphenous vein graft (RSVG) to RCA, RSVG to marginal coronary artery, RSVG to LAD and left internal mammary artery (LIMA) to diagonal coronary artery. Patient had a postoperative bleeding for which he was operated again with successful control of the bleeding. He was symptom-free for the next 12 years. 12 years later, he presented with exertional angina and a positive stress test for which he was taken for cardiac catheterization.

The RSVG to RCA and the LIMA to diagonal branch were normal. Left anterior descending artery angiography showed a stenosis of $75 \%$ $80 \%$ distal to the anastomosis with multiple fistulous communications between the saphenous vein graft

\section{Corresponding Author: Christian GERGES}

Email: christiangergess@hotmail.com

Received: April 30, 2014 | Accepted: February 9, 2016 | Published Online: March 10, 2016

This is an Open Access article distributed under the terms of the Creative Commons Attribution License (creativecommons.org/licenses/by/3.0)

Conflict of interest: None declared | Source of funding: Nil | DOl: http://dx.doi.org/10.17659/01.2016.0026 
and the left upper lobe pulmonary vein via pleural vessels [Fig.1]. There was angiographic evidence of coronary steal phenomenon with decreased antegrade flow in the distal part of left anterior descending artery. We concluded that the degree of coronary steal on top of the distal stenosis was significant enough to cause coronary ischemia.

Considering the presence of multiple fistulous communications between the saphenous vein graft and the pulmonary vasculature with the distal stenosis, coil occlusion of feeders was not considered. Instead, the patient underwent coronary angioplasty with stent implantation (stent Cypher $2.5 \times 13 \mathrm{~mm}$ ) to the distal lesion in left anterior descending artery with good result [Fig.2]. He is symptom-free at 5 years of follow up.

\section{Discussion}

The evolution of the internal mammary artery and the saphenous vein grafts in the coronary artery bypass surgeries still has lots of secrets to understand. The formation of fistulous connection between those grafts and the pulmonary vasculature, many years after the coronary artery bypass graft (CABG), is a rare event. Those fistulas can vary widely in their anatomy. Cases of internal mammary fistulas to pulmonary vein, pulmonary artery, pulmonary parenchyma and even coronary vein have been reported $[3,4]$. The cases of saphenous veins fistulas have been more frequently associated with aneurysmal veins communicating with pulmonary vessels or cardiac chambers [5].

The pathogenesis of these fistulas is not fully understood. Several etiologies have been proposed. It is usually secondary to coronary revascularization, trauma, inflammation, infection or neoplasia [6]. Some case reports suggest that it is related to electrocoagulation instead of clipping the internal mammary artery [7]. It is also suggested that the inflammatory response from disruption of the pleura

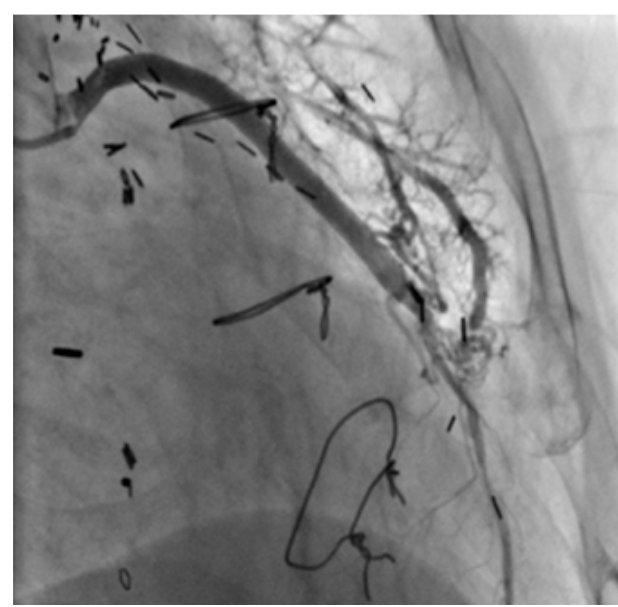

Fig.1: Selective angiogram of the RSVG to the LAD artery showing dense filling of collaterals connecting it to the pulmonary vasculature. Obstructive lesions are noted in the distal LAD.

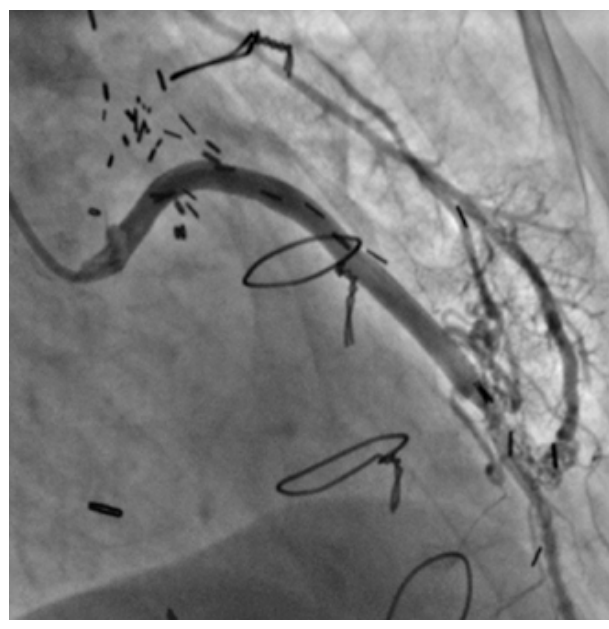

Fig.2: Coronary angiogram of the RSVG to the LAD bypass after coronary angioplasty and stenting of the distal LAD.

during surgery and subsequent neovascularization can lead to multiple communications between grafts and pulmonary vasculature [8].

When symptomatic, the events associated with those fistulas are caused by a coronary steal phenomenon [1]. This phenomenon, resulting in 
ischemia, is due to a hemodynamically significant shunt. When a coronary stenosis appears distally to a fistula it can aggravate the problem even more. To verify the presence of a coronary steal syndrome, we should look into the symptomatic status, angiography, demonstration of ischemia by radionucleotide studies and most specifically by Doppler flow wires. The symptoms associated with the coronary steal syndrome can range from stable angina to acute coronary syndrome and contribute significantly to morbidity. Excessive shunt may result in volume overload of ventricle leading to cardiac failure, depending upon magnitude of shunt. Excessive shunt can be quantified by oximetry or assessed indirectly using echocardiography for presence of volume overload of ventricle.

The best strategy to manage this condition depends on the gravity of the problem. Many options has been described in the English literature: surgical ligation of all the collateral channels [9], percutaneous occlusion of the feeding channels using coils $[10,11]$ or conservative medical management [1]. However we felt that the component of coronary ischemia alone needs to be addressed if the shunt is not hemodynamically significant and further sternotomy can be avoided. In our case, stenting of the native coronary vessel percutaneously revealed to be a good option to treat the vein graft to pulmonary artery fistula. To our knowledge, native vessel percutaneous coronary intervention as a treatment strategy for fistula causing coronary steal phenomenon has only been reported once [12].

\section{Conclusion}

In conclusion, the formation of fistulous connection between the saphenous vein grafts and the pulmonary vasculature are considered as late complications post $C A B G$. They are very rare to occur but should be recognized as a possible cause of recurrent angina. The optimal therapeutic strategy is still controversial.

\section{References}

1. Najm HK, Gill IS, Fitz Gibbon GM, Keon WJ. Coronary-pulmonary steal syndrome. Ann Thorac Surg. 1996;62:264-265.

2. Kimmelstiel CD, Udelson J, Salem D, Rastegar $H$, Bojar R, Konstam MA. Recurrent angina due to a left internal mammary artery-topulmonary artery fistula. Am Heart J. 1993;1 25:234-236.

3. Blanche $C$, Eigler N, Bairey $C N$. Internal mammary artery to lung parenchyma fistula after aortocoronary bypass grafting. Ann Thorac Surg. 1991;52:141-142.

4. de Marchena E, Musial B, Wozniak P, Chakko S, Kessler KM. latrogenic internal mammary artery to coronary vein fistula. Chest. 1990;97:251253.

5. Maher Dabboussi, Yves Assad Saade, Anne Poncet, Bernard Baehrel. Fistula between a Saphenous Vein Graft Aneurysm and the Pulmonary Artery Trunk. Ann Thorac Surg. $2001 ; 71: 1356-1358$.

6. Peter Arley Arrais, Ferreira Alexander C, Zelnick Kenneth, Sangosanya Afolabi, Chirinos Julio, de Marchena Eduardo. Internal mammary artery to pulmonary vasculature fistula-case series. Int J Cardiol. 2006; 108:135-138.

7. Wood MK. Internal mammary artery to lung parenchyma fistula. Ann Thorac Surg. 1992;54:603.

8. Groh WJ, Hovaguimian H, Morton MJ. Bilateral internal mammary to pulmonary artery fistulas after coronary operation. Ann Thorac Surg. 1994;57(6): 1642-1643.

9. Johnson JA, Schmaltz R, Landreneau RJ, Wright WP, Curtis JJ, Walls JT, et al. Internal mammary artery graft to pulmonary vasculature fistula: a cause of recurrent angina. Ann Thorac Surg. 1990;50:297-298. 
10. Nielson JL, Kang PS. Endovascular treatment of a coronary artery bypass graft to pulmonary artery fistula with coil embolization. Cardiovasc Intervent Radiol. 2006;29:302-305.

11. Rajiv, P Talwar VK, Jain R, et al. Left internal mammary artery to pulmonary vasculature fistulae closed with particle embolizaton: new form of percutaneous intervention. Indian Heart
J. 2005;57:725-727.

12. Bijulal S, Namboodiri N, Nair K, Ajitkumar VK. Native vessel angioplasty as treatment strategy for left internal mammary artery to pulmonary vasculature fistula producing coronary steal phenomenon. Int J Cardiol. 2009;20:133(1):e25-27. 